\title{
Derecho de Consumo
}

Rodrigo Momberg Uribe

Universidad de Oxford

Universidad Católica del Norte

LA EMPRESA COMO CONSUMIDORA: ÁMBITO DE APLICACIÓN DE LA LPC, NULIDAD DE CLÁUSULAS ABUSIVAS Y DAÑO MORAl. Corte de APELACiOnes de TALCA, ROL No 674-2014 y CORTE SuPREMA, ROL N $\mathrm{N}^{\circ} 31.709-14$

Es común, especialmente en Derecho Comparado, preguntarse por la utilidad de la dogmática jurídica para los operadores del Derecho, en particular, abogados y jueces. La cuestión que siempre surge es si las publicaciones en libros y revistas especializadas tienen alguna trascendencia para la práctica del Derecho, o si son solo ejercicios intelectuales que no trascienden más allá de algún restringido ámbito académico. En otras palabras, si alguien lee lo que los académicos escriben.

La sentencia que se comenta puede ser paradigmática para estos efectos. En ella se resuelven algunos temas que han sido ampliamente debatidos por la doctrina nacional y comparada, pero que parecen pasar inadvertidos tanto para las partes como para los tribunales que decidieron la cuestión. Como adelanto, una lectura lega de los fallos de la Corte de Apelaciones y de la Corte Suprema podría suponer que en Chile no hay problemas para que una empresa recurra a la LPC en calidad de consumidora, que es posible declarar inválida una cláusula de un contrato después de trece años de celebrado, y que puede otorgarse a una persona jurídica una indemnización por el daño moral consistente en la sensación de vulnerabilidad y aflicción que a uno de sus miembros le produce el incumplimiento de un contrato. A continuación se examinan estas, por decir lo menos, sorprendentes afirmaciones.

\section{1.- LOS HECHOS}

En julio de 2001, Milad y Compañía Ltda. y ADT Security Services S.A. celebraron el contrato denominado de servicios de supervisión remota de alarmas, en virtud del cual la segunda se obligaba a supervisar, a través de diversos medios tecnológicos, la seguridad de dos establecimientos de la primera. En abril de 2013, dichos establecimientos fueron objeto de robos, sin que ello fuese detectado por el sistema de alarmas instalado. Debido a lo anterior, se interpuso denuncia infraccional y demanda civil ante el JPL respectivo, por infracción a los arts. 12 y 23 de la LPC, alegándose que ADT no había respetado los términos 
y condiciones del contrato, prestando un servicio deficiente que produjo perjuicios materiales y morales a la empresa denunciante.

En su defensa, la empresa de seguridad alegó que se habían cortado de raíz los cables telefónicos a través de los cuales se transmitían las señales del sistema de alarma, por lo que no recibió ninguna señal de emergencia o de activación. Sostuvo que como su única obligación era monitorear las señales de alarma y dar cuenta de ellas al suscriptor o a las autoridades correspondientes, al estar impedida de recibir tales señales por la acción de terceros, no se había producido incumplimiento contractual alguno. Agregó que expresamente la cláusula novena del contrato la eximía de responsabilidad en caso de que se produjese la situación descrita.

La sentencia de primera instancia rechazó la denuncia y la demanda civil. La Corte de Apelaciones de Talca revocó el fallo, admitiendo la denuncia por infracción a los arts. 12 y 23 de la LPC, y acogiendo la demanda civil solo en lo relativo al daño moral sufrido por la empresa denunciante. Por último, la Corte Suprema rechazó el recurso de queja interpuesto en contra de la sentencia de segunda instancia.

\section{2.- LA EMPRESA COMO CONSUMIDORA}

Lo primero que llama la atención del caso es que la denunciante y demandante civil es una persona jurídica, particularmente una sociedad comercial. La posibilidad de que una empresa pueda tener la calidad de consumidora $y$, por tanto, acogerse al estatuto de protección, ha sido discutida tanto en Chile como en Derecho Comparado ${ }^{1}$.

$\mathrm{Al}$ efecto, cabe recordar que el art. $1 \mathrm{~N}^{\circ} 1$ de la LPC, al definir consumidor, incluye en forma expresa a las personas jurídicas, por lo que una de las objeciones formales que habitualmente se hacen en Derecho Comparado a la inclusión de la empresa como consumidora, no procede en nuestro país. Sin embargo, la ley $\mathrm{N}^{\mathrm{O}}$ 20.416 introdujo un segundo párrafo a la citada norma, el cual dispone:

"En ningún caso podrán ser considerados consumidores los que de acuerdo al número siguiente deban entenderse como proveedores".

De esta manera, solo aquellas personas jurídicas que no sean proveedores en el sentido que los define el $\mathrm{N}^{\circ} 2 \mathrm{del}$ mismo artículo, podrán en la eventualidad ser considerados consumidores. Ello limita bastante la posibilidad que una persona jurídica pueda ser consumidora, descartando desde ya a aquellas que persigan fines de lucro ${ }^{2}$.

Sin embargo, en Chile el hecho de que una persona jurídica que persigue fines de lucro no pueda considerarse consumidora, no implica necesaria-

${ }^{1} \mathrm{Al}$ efecto, véase Momberg (2012).

${ }^{2} \mathrm{Si}$ bien en teoría podría pensarse en alguna persona jurídica con fines de lucro que tenga por objetivo alguna actividad distinta a la de producción, fabricación, importación, construcción, distribución o comercialización de bienes o de prestación de servicios a consumidores, la generalidad con que se han definido tales actividades hace que en la práctica ello no sea posible. 
mente que no pueda acogerse a la normativa de la LPC para ejercer sus derechos. Esta anomalía se produce debido a que la ley $N^{\circ} 20.416$, que fija normas especiales para las empresas de menor tamaño, prescribe en su art. $9 \mathrm{~N}^{\circ} 2$ :

\section{"Serán aplicables a los actos y contratos celebrados entre mi- cro o pequeñas empresas y sus proveedores las normas es- tablecidas en favor de los con- sumidores por la ley $\mathrm{N}^{\circ} 19.496$ en los párrafos $1^{\circ}, 3^{\circ}, 4^{\circ}$ y $5^{\circ}$ del Título II, y en los párrafos $1^{\circ}, 2^{\circ}, 3^{\circ}$ y $4^{\circ}$ del Título III o, a opción de las primeras, las demás disposiciones aplicables entre partes".}

El No 3 del citado artículo agrega que las infracciones a la ley $\mathrm{N}^{\mathrm{o}}$ 20.416 serán sancionadas con arreglo al art. 24 de la ley $\mathrm{N}^{\circ}$ 19.496. Hay que recordar que el art. 2 de la ley $\mathrm{N}^{\mathrm{o}} 20.416$ define a las microempresas como aquellas con ingresos anuales no superiores a $2.400 \mathrm{UF}$, y las pequeñas empresas como aquellas con ingresos anuales superiores a 2.400 y que no excedan las 25.000 UF.

Así, la citada norma hace aplicable a los actos o contratos que las micro y pequeñas empresas celebren con sus proveedores una parte considerable de las normas de la LPC. Específicamente, son aplicables las normas contenidas en los párrafos $1^{\circ}$, $3^{\circ}, 4^{\circ}$ y $5^{\circ}$ del título II, esto es, derechos y deberes del consumidor, obligaciones del proveedor, normas de equidad en las estipulaciones y en el cumpli- miento de los contratos de adhesión y responsabilidad por incumplimiento; como también las de los párrafos $1^{\circ}, 2^{\circ}$, $3^{\circ}$ y $4^{\circ}$ del título III, es decir, aquellas relativas a información y publicidad, promociones y ofertas, crédito al consumidor y normas especiales en materia de prestación de servicios. Se agrega que las normas relativas a los medios de prueba contenidas en el Código de Comercio serán también aplicables a los litigios judiciales entre los micro o pequeños empresarios y sus proveedores.

De especial relevancia es lo prescrito en el $\mathrm{N}^{\circ} 6$ del referido artículo, el cual no deja dudas respecto a que las normas de la LPC mencionadas en el párrafo anterior serán aplicables a todos los actos o contratos que las micro o pequeñas empresas ejecuten o celebren, aun cuando ellos formen parte o se relacionen directamente con su giro principal $^{3}$. En otras palabras, para la ley $\mathrm{N}^{\mathrm{O}} 20.416$ el criterio relevante para determinar la aplicación de la LPC es la calidad de las partes que intervienen en el contrato sin que importe la finalidad u objeto del mismo. Así, si una de las partes es una micro o pequeña empresa (según las define el artículo segundo inciso segundo de la ley $\mathrm{N}^{\mathrm{O}}$ 20.416) y la otra un proveedor (de acuerdo con la definición del art. $1 \mathrm{~N}^{\circ} 2$

${ }^{3}$ El N ${ }^{\circ} 6$ del citado artículo señala: "Deber de Profesionalidad. Si las infracciones a lo dispuesto en este artículo se refieren a la adquisición o contratación de bienes o servicios que se relacionan directamente con el giro principal de la micro o pequeña empresa, el tribunal deberá considerar en la aplicación de la multa que proceda, que el deber de profesionalidad de la micro o pequeña empresa es equivalente al del proveedor que cometió la infracción". 
de la LPC) las normas ya señaladas de la LPC se aplicarán necesariamente a tal relación contractual ${ }^{4}$.

No hay en los fallos de la Corte de Apelaciones ni de la Corte Suprema indicación a que la aplicabilidad de la LPC haya sido cuestionada por la calidad de empresa de la denunciante. Sin perjuicio de lo anterior, tampoco hay referencia alguna a las normas de la ley $\mathrm{N}^{\mathrm{o}} 20.416$, por lo que parece evidente que ni las partes ni los tribunales se representaron la posibilidad (imperativa si es que la denunciante era una micro o pequeña empresa, lo que no es posible discernir del texto de las sentencias) que las normas de dicha ley se aplicasen al caso en cuestión. Ello demuestra la escasa difusión que la mencionada ley ha tenido entre los operadores jurídicos, cuestión que, sin duda, menoscaba los objetivos que dicha normativa se propuso. Asimismo, una adecuada aplicación de la normativa legal correspondiente por parte de los tribunales, contribuiría a que las partes tuviesen certeza respecto al estatuto legal que les es aplicable.

\section{3.- LA NULIDAD}

DE LAS CLÁUSULAS ABUSIVAS

Como se dijo, una de las defensas esgrimidas por ADT fue la existencia de una cláusula eximente de responsabilidad, que se aplicaría justamente en la situación alegada por la denunciante. $\mathrm{Al}$ respecto, la Corte de Apelaciones

${ }^{4}$ Según el N ${ }^{\circ} 2$ del mencionado art. 9, la aplicación de las normas respectivas de la LPC es irrenunciable para las micro o pequeñas empresas.

de Talca en el considerando octavo de la sentencia que se comenta señala:

"Que las cláusulas en las que el demandado se apoya para sostener que no es responsable de lo sucedido, deben tenerse por no válidas $\mathrm{y}$, por consiguiente, son ineficaces para los fines del presente contrato, toda vez que vulneran la naturaleza del mismo, desde que buscan excluir el deber de responder allí donde, efectivamente, debe responder, de modo que las obligaciones contraídas por ADT son tales, predominan y no pueden ceder ante la excepción incluida en un contrato que, por lo demás, es de adhesión, pues de aceptarse dicha exclusión desaparecería la obligación medular que asumió y que constituye la prestación central bajo cuyo imperio pactó el demandante".

Ante esta resolución, la demandada interpuso recurso de queja basado en que la denunciante no había interpuesto la acción de nulidad contenida en los arts. 16 y 16B de la LPC, por lo que la Corte de Apelaciones carecía de competencia para pronunciarse sobre la nulidad de la citada cláusula. La Corte Suprema desechó tal recurso, señalando que al haberse alegado por la demandada la validez de tales cláusulas para eximirse de responsabilidad, la Corte de Apelaciones se pronunció sobre una defensa, sin que exista falta o abuso en ello.

Lo cierto es que la lectura del citado considerando octavo genera más dudas 
que certezas. En primer lugar, la Corte declara que ciertas cláusulas del contrato

"deben tenerse por no válidas, y por consiguiente, son ineficaces".

El lenguaje utilizado es, a lo menos, impreciso. ¿Debe entenderse que tales cláusulas son nulas? ¿ O la Corte está pensando en otra causal de ineficacia? Si fuesen nulas, ¿se trata de una nulidad absoluta, relativa o sui generis?

La Corte hace referencia a que se trata de un contrato de adhesión, por lo que siendo una relación contractual regulada por la LPC, deberían aplicarse los art. 16 y 16B. Al respecto, es discutido en doctrina nacional cual es la naturaleza de la nulidad que tales normas prescriben ${ }^{5}$. La mayoría de la doctrina, basada en la naturaleza de orden público de la normativa de protección al consumidor, el carácter prohibitivo del art. $16 \mathrm{y}$ en el hecho de ser una cuestión relativa a la naturaleza del contrato, se inclina por señalar que se trataría de una nulidad de carácter absoluto. Al carecer de regulación propia en la LPC, esta nulidad estaría regida por la normativa del Código Civil. Sin embargo, otros han planteado que se trataría de un régimen de nulidad autónomo, no sujeto a las reglas de la nulidad absoluta del Derecho Común? .

\footnotetext{
${ }^{5}$ Hasta antes de la modificación introducida por la ley $\mathrm{N}^{\circ} 19.955$, podía dudarse si la sanción era la inexistencia o la nulidad de las cláusulas abusivas, pero el texto de los arts. $16 \mathrm{~A}$ y $16 \mathrm{~B}$ deja en la actualidad claro que se trata de una especie de nulidad. Ello fue confirmado por el art. 17E, introducido por la ley $\mathrm{N}^{\mathrm{o}} 20.555$.

${ }^{6}$ Por todos, véase Pizarro (2013), pp. 352353.

${ }^{7}$ Contardo (2013), Baraona (2014).
}

Como se dijo, la Corte no resuelve el asunto, ni tampoco señala expresamente cual sería la causal para declarar tal cláusula como abusiva y, por tanto, ineficaz. En una redacción confusa, parece indicar que la cláusula eximente de responsabilidad vulnera la naturaleza del contrato porque

"de aceptarse dicha exclusión desaparecería la obligación medular que [ADT] asumió y que constituye la prestación central bajo cuyo imperio pactó el demandante".

La jurisprudencia francesa ha resuelto casos similares, fundándose en que una cláusula eximente o limitativa de responsabilidad por inejecución de la obligación principal del deudor, priva de objeto a tal obligación y por tanto, de causa a la del acreedor ${ }^{8}$. Sin embargo, más fácil (y preciso) hubiese sido que la Corte se remitiese al art. 16 letra e), que sanciona como abusivas las cláusulas de limitación absoluta de responsabilidad que priven al consumidor de su derecho a resarcimiento por deficiencias que afecten la utilidad o finalidad esencial del producto o servicio.

Los temas que el tribunal elude no son meras disputas doctrinales. Pueden tener importantes consecuencias en la práctica. Desde luego será relevante determinar cuál es el estatuto que rige la nulidad de las cláusulas abusivas, por ejemplo, para determinar la legitimación activa y el plazo de pres-

${ }^{8}$ Com. 22 de octubre de 1996; D. 1997, p. 121, note Alain Sèrieux; RTD civ. 1997, p. 148, obs. Jacques Mestre. 
cripción de la misma. En el caso que se comenta, al parecer la Corte de Apelaciones de oficio declara, usando sus propias expresiones, la ineficacia o invalidez de la cláusula, ya que no consta que la denunciante lo haya solicitado. Por otra parte, el contrato se había celebrado en 2001, y la sentencia se dicta en 2014, por lo que se puede presumir que habían transcurrido más de diez años entre la celebración del contrato y la notificación de la denuncia y demanda civil. El plazo de prescripción de la nulidad absoluta había entonces transcurrido con creces, por lo que puede presumirse que el tribunal descarta que se trate de ese tipo de nulidad. Al efecto, es plausible plantear que una cláusula contraria al derecho y a la buena fe no debería poder sanearse por el mero 284 lapso, ya que eso implicaría legitimar el abuso de una parte hacia la otra ${ }^{9}$. Sin embargo, la falta de pronunciamiento expreso sobre tales cuestiones mantiene la incertidumbre.

\section{4.- LA EMPRESA COMO TITULAR DEL DAÑO MORAL}

De la sentencia en comento, se puede deducir que el proveedor incumplió el contrato (en palabras de la Corte de Apelaciones, "prestó un servicio deficiente"). Ante la demanda de indemnización de perjuicios por dicho incumplimiento, la Corte desestima la reparación del daño emergente, pero admite el moral. Hay que recordar que el caso se encuentra regido por la LPC, que en su art. 3 letra e) admite de

\footnotetext{
${ }^{9}$ En contra Pizarro (2013), p. 354.
}

manera expresa el derecho del consumidor a ser indemnizado de todos los daños materiales y morales derivados del incumplimiento de las obligaciones del proveedor, por lo que no debería haber mayor discusión en cuanto a su procedencia en sede contractual (probada la existencia del daño y su relación causal con el incumplimiento).

Lo más llamativo del fallo es el criterio por el cual se concede el daño moral a la empresa. Al efecto, la Corte de Apelaciones señala:

" $\left.11^{\circ}\right)$ Que, en cambio, debe admitirse la indemnización por daño moral, pues es evidente que la falta de previsión o descuido de dicha empresa, provocó una sensación de vulnerabilidad respecto de la cual se creía estar protegido y causó aflicción cierta, en este caso, al actor en su calidad dueño o socio de los establecimientos afectados, la que por su naturaleza debe regularse de modo prudencial, estimándose justa la suma de \$10.000.000 (diez millones de pesos) demandada en autos" 10 .

La posibilidad de que una persona jurídica pueda sufrir daño moral indemnizable es todavía debatida. Quizá la posición más aceptada hoy sea aquella que admite la reparación del daño moral sufrido por una persona jurídica, cuando aquel tiene consecuencias patrimoniales, descartándose la indem-

${ }^{10}$ Hay que aclarar que "el actor" era la empresa y no el dueño o socio, como equivocadamente se indica en el fallo. 
nización del denominado daño moral puro, el cual solo serían susceptibles de sufrir las personas naturales. La indemnización del daño moral en el caso de una empresa se reduciría entonces a aquellas situaciones en que el hecho ilícito ha lesionado su prestigio o imagen comercial, causándole, a su vez, un menoscabo patrimonial. Así lo decidió la Corte Suprema en el conocido caso Zorín (considerando decimoséptimo):

"Para pretender ser indemnizado por el daño a la imagen de una empresa, es necesario demostrar que ha existido lesión a la imagen de una empresa, y acreditar, de una manera cierta, las consecuencias económicas en que se ha traducido ese desprestigio" $"$.

Esta tendencia ha sido criticada, ya que implicaría resarcir por vía de un supuesto daño moral, perjuicios que son de naturaleza patrimonial, pero con frecuencia de difícil prueba ${ }^{12}$. Se trataría, en la mayoría de los casos, del resarcimiento del lucro cesante representado por las utilidades futuras que la empresa ha dejado de percibir por el daño a su prestigio o imagen comercial.

En el caso en comento, la Corte derechamente confunde las cosas al estimar que el eventual daño moral que el incumplimiento puede producir a una persona natural que es parte de la empresa ("dueño o socio" según la sentencia), es transferible a esta última

${ }^{11}$ Zorín S.A. con Compañía Siderúrgica Huachipato S.A. (2012).

${ }^{12}$ Barrientos (2007); Gómez (2002). $y$, por tanto, indemnizable como un daño moral sufrido por la empresa. En otras palabras, a juicio de la Corte, la aflicción que sufre un miembro de una persona jurídica por el incumplimiento de un contrato en el cual esta última es acreedora, puede ser reclamado por la persona jurídica a título de daño moral propio. Ello resulta, por decir lo menos, sorprendente. La Corte Suprema, al decidir el recurso de queja, no entra al fondo de la cuestión y se limita a señalar que siendo la indemnización del daño moral de las personas jurídicas una cuestión debatida,

"los magistrados han procedido en uso de la facultad privativa que les confiere la ley en la interpretación de las normas jurídicas, en relación a las situaciones de hecho que deben conocer, circunstancia que de modo alguno constituye falta o abuso grave que justifique su reparación disciplinaria" (considerando cuarto).

Este es el punto más criticable de la sentencia. Es por completo improcedente el conceder daño moral a una persona jurídica por el daño moral que eventualmente sufren sus miembros. La demanda civil debió haber sido rechazada en este punto. Es una cuestión jurídica básica el que la persona jurídica constituye una entidad distinta a sus miembros considerados de manera individual. Así lo estipula expresamente el art. 2053 del Código Civil, y así también lo ha reconocido la propia Corte Suprema: 
"El artículo 2053 del Código Civil, en su inciso segundo dispone: 'La sociedad forma una persona jurídica, distinta de los socios individualmente considerados'. En consecuencia, no es posible extender el daño sufrido por la Sociedad de Transportes Jorquera Limitada a los socios que la integran por el solo hecho de tener tal calidad, desde que ello importaría una confusión entre la persona jurídica que es la sociedad, y las personas naturales que la forman"13.

Incluso, la Corte de Apelaciones de Santiago, en un caso con hechos casi idénticos al que se comenta, seguido también en contra de ADT por incumplimiento del servicio de supervisión remota de alarmas, había decidido que:

"en cuanto al daño moral, quien demanda es una persona jurídica, no obstante se fundamenta el daño en la inseguridad permanente generada frente a la posibilidad de nuevos robos, lo que resulta del todo improcedente". (considerando décimo $)^{14}$

La concesión del daño moral en el caso que se comenta parece traslucir algunos propósitos encubiertos, que

${ }^{13}$ Sociedad de Transportes Jorquera Limitada con Banco Sudamericano (2006). En el mismo sentido, véase la causa penal rol 10.67714 (2014).

${ }^{14}$ Snack Adventure Alimentos Limitada con ADT Secutiry Services S.A. (2014). los tribunales, quizá de manera inconsciente, buscan lograr en casos en que el daño patrimonial es irrelevante o de difícil acreditación: sancionar conductas que se consideran reprochables y eludir las dificultades probatorias del daño emergente y en particular, del lucro cesante ${ }^{15}$. A ello debe agregarse que en materia de responsabilidad contractual, la previsibilidad del daño moral debiese examinarse con parámetros especialmente estrictos. Por ello, la concesión sin mayores fundamentos del daño moral, como en el fallo en cuestión, y que además es inconsistente con jurisprudencia anterior, no hace más que perjudicar uno de los valores primarios de todo sistema jurídico, cual es la seguridad jurídica, afectando de manera seria la predictibilidad que respecto a futuras disputas deben tener las partes al planificar sus relaciones contractuales.

\section{Bibliografía CitADA}

BARAONA, Jorge (2014). "La nulidad de las cláusulas abusivas en la ley $\mathrm{N}^{\circ} 19.496$ : naturaleza y régimen", en Francisca BARRIENTOS (coord.). Condiciones generales de la contratación y cláusulas abusivas. Santiago: Ediciones Universidad Diego Portales.

BarRientos, Marcelo (2007). "Negación de daños morales a una persona jurídica en materia contractual". Revista Chilena de Derecho. Vol. 34. $\mathrm{N}^{\mathrm{o}}$ 1. Santiago.

Contardo, Juan Ignacio (2013). "Comentario de Sentencia Sernac con Cencosud". Revista Derecho Público

\footnotetext{
${ }^{15}$ En este sentido, Gómez (2002).
} 
Iberoamericano. Año II. No 3. Santiago.

Gómez Pomar, Fernando (2002). "Comentario a la sentencia del Tribunal Supremo, Sala 1 ${ }^{\mathrm{a}}$, 20.02.2002: el daño moral de las personas jurídicas". InDret, Vol. 4. Barcelona.

Momberg, Rodrigo (2012). "La transformación de la ley de protección de los derechos de los consumidores en la norma común del derecho de contratos chileno", en Fabián Elorriaga, (ed.). Estudios de Derecho Civil VII, Santiago: Editorial LexisNexis Chile.

Pizarro, Carlos (2013). "Articulo 16 A", en Iñigo DE LA MAZA, y Carlos PizARRO (dirs.). La protección de los derechos de los consumidores. Santiago: Thomson Reuters

\section{Jurisprudencia citada}

Sociedad de Transportes Jorquera Limitada con Banco Sudamericano (2006). Corte Suprema, 30 de noviembre de 2006, rol 7-05.

Zorín S.A. con Compañía Siderúrgica Huachipato S.A. (2012). Corte Suprema, 31 de octubre de 2012, rol 3325-12

Causa penal (2014). Corte Suprema, 12 de agosto de 2014, rol 10.677-14.

Snack Adventure Alimentos Limitada con ADT Secutiry Services S.A. (2014). Corte de Apelaciones de Santiago, 15 de octubre de 2014, rol 468-2014.

Com. 22 de octubre de 1996; D. 1997, p. 121, note Alain Sèrieux; RTD civ. 1997, p. 148, obs. Jacques Mestre. 